\title{
Polyphenol (-)-epigallocatechin gallate targeting myocardial reperfusion limits infarct size and improves cardiac function
}

\author{
Chan Jin Kim, Jin Mo Kim, Seung Ryong Lee ${ }^{1}$, Young Ho Jang ${ }^{2,3}$, June Hong Kim³ , and Kook Jin Chun ${ }^{3}$ \\ Departments of Anesthesiology and Pain Medicine, ${ }^{1}$ Pharmacology, School of Medicine, Keimyung University, ${ }^{2}$ Department of \\ Anesthesiology and Pain Medicine, Pureun Hospital, Daegu, ${ }^{3}$ Institute of Cardiovascular Research, Pusan National University Hospital, \\ Yangsan, Korea
}

Background: This experiment was performed to determine the effect of polyphenolic (-)-epigallocatechin (EGCG), the most abundant catechin of green tea, given at reperfusion period.

Methods: Isolated rat hearts were subjected to $30 \mathrm{~min}$ of regional ischemia and $2 \mathrm{~h}$ of reperfusion. Green tea extract (GT) was perfused with the following concentrations; 0, 0.5, and $1 \mu \mathrm{M}$ (GT-O, GT-0.5, and GT-1, respectively). In a next experiment, hearts were assigned randomly to one of the following groups; Control, EGCG-1 ( $1 \mu \mathrm{M}$ of EGCG), and EGCG-10 (10 $\mu \mathrm{M}$ of EGCG). GT and EGCG were perfused for a period of 5 min before and 30 min after reperfusion. For comparison of cardioprotection among groups, morphometric measurement was performed by 2,3,5-triphenyltetrazolium chloride staning.

Results: GT $1 \mu \mathrm{M}(10.3 \pm 2.1 \%, \mathrm{P}<0.05)$ significantly reduced infarct volume as a percentage of ischemic volume compared to untreated hearts $(27.4 \pm 1.1 \%)$. EGCG $10 \mu \mathrm{M}(13.2 \pm 4.0 \%)$ significantly reduced myocardial infarction compared to control hearts $(27.2 \pm 1.4 \%, \mathrm{P}=0.002)$. After $2 \mathrm{~h}$ of reperfusion, cardiodynamic variables, including left ventricular developed pressure, rate-pressure produce, $+\mathrm{dP} / \mathrm{dt}_{\max }$, and $-\mathrm{dP} / \mathrm{dt}_{\min }$ were significantly improved by $10 \mu \mathrm{M}$ of EGCG compared to control hearts ( $\mathrm{P}=0.01,0.016,0.009$, and 0.019 , respectively).

Conclusions: EGCG treatment at an early reperfusion period reduces myocardial infarction and improves cardiodynamics in isolated rat hearts. (Korean J Anesthesiol 2010; 58: 169-175)

Key Words: (-)-Epigallocatechin gallate, Green tea, Myocardium, Reperfusion injury.

Received: July 27, 2009. Revised: 1st, August 12, 2009; 2nd, August 18, 2009. Accepted: September 24, 2009.

Corresponding author: Young Ho Jang, M.D., Ph.D., Department of Anesthesiology and Pain Medicine, Pureun Hospital, 2033-13, Daemyung2dong, Nam-gu, Daegu 705-032, Korea. Tel: 82-53-427-8275, Fax: 82-53-471-2806, E-mail: weonjo@pnuyh.co.kr

This article is a Master's Thesis by Chan Jin Kim.

@) This is an open-access article distributed under the terms of the Creative Commons Attribution Non-Commercial License (http:// creativecommons.org/licenses/by-nc/3.0/), which permits unrestricted non-commercial use, distribution, and reproduction in any medium, provided the original work is properly cited. 


\section{Introduction}

Green tea has been known for a long time to have antioxidant [1], antimicrobial [2], anti-inflammatory [3], antiallergic [4], and anticarcinogenic [5] properties, and there is a great deal of interest in its bioregulatory effects. Green tea has vasodilatory effects [6], can inhibit the development of arteriosclerosis [7], and there is evidence that it reduces the incidence of cardiac diseases [8].

The main bioactive substances of green tea consist of (-)-epigallocatechin-3-gallate (EGCG), (-)-epigallocatechin (EGC), (-)-epicatechin-3-gallate (ECG), and (-)-epicatechin (EC)-like polyphenolic epicatechin. EGCG is the most abundant catechin in green tea, and has the highest biological activity [9]. In animal models, EGCG administration has been shown to inhibit the cerebral and renal ischemic injury $[10,11]$.

Recently, it has been reported that EGCG can protect the heart from cardiac ischemic injury [12]. However, in actual clinical cases, acute myocardial infarction patients already have cardiac ischemic injury when they are admitted to the hospital, and it is impossible to administer therapeutic drugs before an unexpected acute myocardial infarction occurs. Therefore, practical treatment of acute myocardial infarction would include administration after acute coronary artery occlusion or during reperfusion. The administration of EGCG during reperfusion has been reported to reduce cardiac reperfusion injury [13]; however, there have not yet been any studies on the extent that EGCG reduces myocardial necrosis, an indicator of reperfusion injury.

In this study, EGCG was administered to isolated rat hearts during coronary artery reperfusion, and the effects of EGCG on myocardial necrosis and cardiac hemodynamics were analyzed.

\section{Materials and Methods}

\section{Isolated heart perfusion using the Langendorff system}

The proposed study was approved by the ethics committee of our institution. Coronary perfusion by the Langendorff system with modified Krebs-Henseleit (KH) buffer solution, containing $118.5 \mathrm{NaCl}, 4.7 \mathrm{KCl}, 1.2 \mathrm{MgSO}_{4}, 1.8 \mathrm{CaCl}_{2}, 24.8 \mathrm{NaHCO}_{3}, 1.2$ $\mathrm{KH}_{2} \mathrm{PO}_{4}$, and 10 glucose (in mM), was performed. $\mathrm{KH}$ buffer was freshly prepared and filtered through a $2.0 \mu \mathrm{m}$ microfilter (Nalge Nunc International Corp., Rochester, NY, USA). The KH buffer was added to the Langendorff apparatus, and $30 \mathrm{~min}$ before the experiment, the buffer was bubbled with $95 \% \mathrm{O}_{2}$ and $5 \% \mathrm{CO}_{2}$, so that $\mathrm{pH}$ would be about 7.4. The Langendorff system was maintained at $38^{\circ} \mathrm{C}$ by a water circulation pump.

Male Wistar rats (Korea Taconic Co., Daegu, Korea) weighing
280-330 g were anesthetized by an intraperitoneal injection of $100 \mathrm{mg} / \mathrm{kg}$ pentobarbital sodium (Entobar ${ }^{\circledR}$, Hanlim Pharceuticals, Yongin, Korea), and 300 IU heparin was also administered. After each rat was anesthetized and no longer responsive to noxious stimulus to the tail, a median thoracotomy was performed. Within 1 min of heart removal, the heart was immediately connected to the Langendorff system via the aorta, and perfused with modified $\mathrm{KH}$ buffer solution, allowing for coronary flow. The perfusion pressure was set at $100 \mathrm{cmH}_{2} \mathrm{O}$ above the heart.

Drainage of coronary perfusate from the right side of the heart was collected in a graduated cylinder to measure coronary perfusion. To measure ventricular function, a balloon was inserted into the left ventricle (LV) through the left atrium. The balloon was coupled to a graded threaded micro-syringe and balloon volume was adjusted to give a left ventricular enddiastolic pressure (LVEDP) of 5-10 $\mathrm{mmHg}$ at the beginning of the experiment. The left ventricular developed pressure (LVDP) was calculated from the difference between the left ventricular systolic pressure (LVSP) and LVEDP. The rate-pressure product (RPP) was calculated by multiplying the heart rate by the LVDP. Hemodynamic parameters, including $+\mathrm{dP} / \mathrm{dt}_{\max }$ and $-\mathrm{dP} / \mathrm{dt}_{\text {min }}$, were determined using an MP150 pressure transducer (BioPac Systems, Santa Barbara, CA, USA).

\section{Inducing regional ischemia}

Ischemia was induced after the heart had been connected to the Langendorff system and a minimum of $30 \mathrm{~min}$ of stabilization had elapsed. To induce regional ischemia, a 6-0 polypropylene suture was looped around the proximal segment of the left coronary artery, and both ends of the suture were threaded through a $1 \mathrm{~cm}$ PE50 tube to form a snare loop. Ischemia was triggered by pulling the thread of the snare and blocking coronary artery flow. Reperfusion was induced by relaxing the snare. After reperfusion, if ventricular fibrillation (VF) occurred, there was usually spontaneous reversion to normal sinus rhythm within $30 \mathrm{sec}$. If the duration of VF was longer than $30 \mathrm{sec}$, the heart was treated with finger flick cardioversion until a perfusing rhythm was obtained.

\section{Test substances}

Green tea extracts were made using dried commercial green tea leaves (Boseung green tea Myeongga, Gwangju, Korea). Ten milliliters of water containing $0.2 \mathrm{~g}$ green tea were heated to $60^{\circ} \mathrm{C}$ and stirred for $5 \mathrm{~min}$. The leaves were then removed by filtering, and the solution was freeze-dried to obtain the green tea extract (GT) used in the experiment. GT and EGCG (SigmaAldrich Chemical Co., St. Louis, MO, USA) were each dissolved 
in distilled water to make less than $2.5 \mathrm{mM}$ stock solutions. The test stock solutions were stored at $4^{\circ} \mathrm{C}$ and diluted on the day of the experiment with $\mathrm{KH}$ buffer to the final concentrations.

\section{Test protocols}

The duration of all episodes of regional ischemia induced in isolated hearts was $30 \mathrm{~min}$ and reperfusion was performed for $2 \mathrm{~h}$. There were 2 experiments, and hearts were randomly assigned to 3 groups for each experiment. For each experiment, either GT or EGCG were administered 5 min before coronary reperfusion to $30 \mathrm{~min}$ after reperfusion for a total of $35 \mathrm{~min}$.

The first experiment was to determine the effects of green tea itself, which is not a pure epicatechin. GT at $0.5 \mu \mathrm{M}$ (GT-0.5, $\mathrm{n}=7)$ and $1 \mu \mathrm{M}(\mathrm{GT}-1, \mathrm{n}=8)$ was administered to isolated rat hearts. After the hearts had undergone $2 \mathrm{~h}$ of reperfusion, the myocardial infarction was compared to the control group where GT was not administered (GT-0, $\mathrm{n}=8$ ).

The second experiment was to determine the effects of EGCG, the main component of green tea. EGCG at $1 \mu \mathrm{M}$ (EGCG-1, $\mathrm{n}=$ 8) and $10 \mu \mathrm{M}$ (EGCG-10, $\mathrm{n}=8$ ) was administered as described, and the myocardial infarction was then compared to the control group where EGCG was not administered (EGCG-0, $\mathrm{n}=9$ ). There were no differences in the body weight and heart weight among the groups (Table 1).

\section{Measurement of area at risk and area of necrosis}

Measurements of the areas at risk (AR) and areas of necrosis (AN) were performed in the same manner as in our previous study [14]. After $2 \mathrm{~h}$ of reperfusion, the snare around the left coronary artery was reoccluded, and $3 \mathrm{~mL}$ of diluted fluorescent polymer microspheres (Duke Scientific Corp., Palo Alto, CA, USA) were slowly infused into the aorta. The hearts were then removed from the Langendorff system, drained, and weighed. They were then frozen for $1-3 \mathrm{~h}$ at $-20^{\circ} \mathrm{C}$. An acrylic rodent heart matrix (Zivic Instruments, Pittsburgh, PA, USA) was used to make $2 \mathrm{~mm}$ transverse sections. The sections were soaked for $20 \mathrm{~min}$ at $37^{\circ} \mathrm{C}$ in $1 \%$ 2,3,5-triphenyltetrazolium chloride (TTC). Colored viable tissue by TTC was distinguished from the noncolored area of myocardial necrosis using $10 \%$ formalin.
For each $\mathrm{LV}, \mathrm{AR}$, and $\mathrm{AN}$, the volume $\left(\mathrm{cm}^{3}\right)$ was calculated by multiplying the area by the width of each specimen $(2 \mathrm{~mm})$. The area of myocardial necrosis was defined as AN/AR. All measurements were performed in a blinded fashion. There were no differences in the volumes of $\mathrm{LV}$, $\mathrm{AR}$, or $\mathrm{AR} / \mathrm{LV}$ values among the groups (Table 1).

\section{Statistical analysis}

The means \pm S.E. were determined for the data. One-way ANOVA, as well as least significant difference tests for later verification, were performed. Values of $\mathrm{P}<0.05$ were considered to be statistically significant. Data analysis was performed using SPSS for Windows, version 12.0.

\section{Results}

A total of 51 rat hearts were used in the experiments. Three hearts were excluded from analysis; 1 heart had an LVDP less than $80 \mathrm{mmHg}$ and 2 hearts had continuous arrhythmias during the stabilization period. Therefore the results of 48 rat hearts

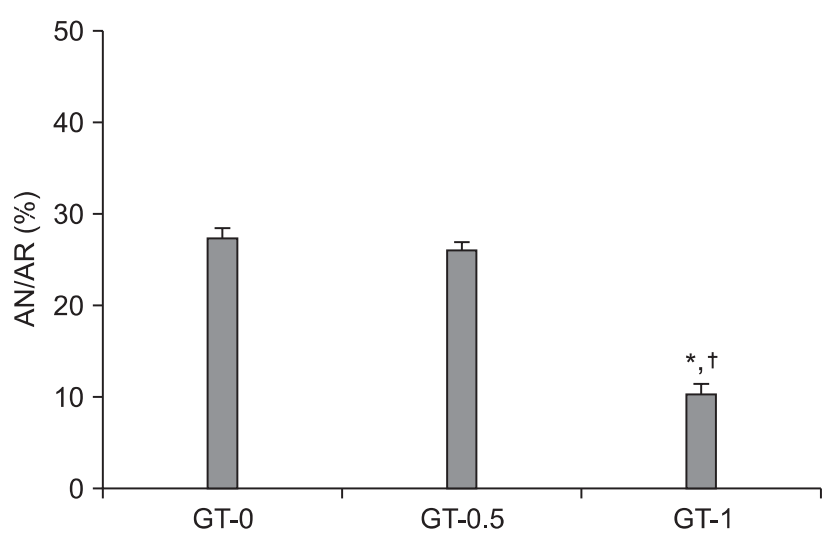

Fig. 1. Area of necrosis (AN) as percentage of area at risk (AR) as evaluated by triphenyltetrazolium chloride staining following $30 \mathrm{~min}$ regional ischemia and $2 \mathrm{hrs}$ reperfusion in isolated rat heart model. GT $1 \mu \mathrm{M}$ treated hearts (GT-1) significantly decrease AN/AR compared to GT-untreated hearts (GT-0) and GT $0.5 \mu \mathrm{M}$ treated hearts (GT-0.5). Values are expressed as mean \pm SEM. ${ }^{*} \mathrm{P}<0.001$ vs. GT- 0 , ${ }^{\dagger} \mathrm{P}<0.001$ vs. GT- 0.5 .

Table 1. Body Weight, Heart Weight, and Morphometric Data

\begin{tabular}{ccccccc}
\hline Group & Body weight $(\mathrm{gm})$ & Heart weight $(\mathrm{gm})$ & LV volume $\left(\mathrm{cm}^{3}\right)$ & AR volume $\left(\mathrm{cm}^{3}\right)$ & AR/LV $(\%)$ & AN volume $\left(\mathrm{cm}^{3}\right)$ \\
\hline EGCG-0 & $303.1 \pm 6.2$ & $1.43 \pm 0.05$ & $0.500 \pm 0.022$ & $0.289 \pm 0.014$ & $58.2 \pm 2.9$ \\
EGCG-1 & $301.6 \pm 9.3$ & $1.43 \pm 0.05$ & $0.496 \pm 0.042$ & $0.282 \pm 0.022$ & $57.8 \pm 3.8$ \\
EGCG-10 & $312.5 \pm 5.5$ & $1.43 \pm 0.04$ & $0.506 \pm 0.029$ & $0.295 \pm 0.028$ & $58.2 \pm 4.5$ & $0.043 \pm 0.014^{*}$ \\
\hline
\end{tabular}

Values are mean \pm SEM. EGCG: polyphenol (-)-epigallocatechin gallate. EGCG-0, EGCG-1, and EGCG-10: 0, 1, and 10 $\mu$ M of EGCG, respectively. LV: left ventricle, AR: area at risk, AN: area of necrosis. There were no significant differences in body weight, heart weight, volumes of LV, AR, and AR/LV among groups. ${ }^{*} \mathrm{P}<0.001$ vs. EGCG- 0 . 
were compared.

In the GT experiment, the AN/AR value for group GT-0.5 was $26.0 \pm 1.2 \%$ and for group GT- 0 was $27.4 \pm 1.1 \%$. There was no significant difference. However, the AN/AR for group GT-1 was $10.3 \pm 2.1 \%$, which was significantly lower than either group GT-0 or GT-0.5 (P $<0.001)$ (Fig. 1).

In the EGCG experiment, 3 hearts from each of the 3 groups developed VF immediately after reperfusion, but immediately reverted to normal sinus rhythm. There were no significant differences in the hemodynamic indicators, LVDP, RPP, $+\mathrm{dP} /$ $\mathrm{dt}_{\max }$, and $-\mathrm{dP} / \mathrm{dt}_{\min }$ during the stabilization period (Table 2). Hemodynamic recoveries in terms of percent changes measured during stabilization and $2 \mathrm{~h}$ after reperfusion were determined in the EGCG groups. The percent change of LVDP for group EGCG-0 and group EGCG-1 were $42.8 \pm 7.0 \%$ and $48.0 \pm 3.3 \%$, respectively, and there was no significant difference between the two groups. However the LVDP for group EGCG-10 was $72.0 \pm 10.5 \%$, which was significantly higher than the LVDP of

Table 2. Baseline Coronary Flow and Cardiodynamic Data

\begin{tabular}{|c|c|c|c|c|c|c|}
\hline Group & $\begin{array}{c}\mathrm{CF} \\
(\mathrm{ml} / \mathrm{min})\end{array}$ & $\begin{array}{c}\text { HR } \\
\text { (beats/min) }\end{array}$ & $\begin{array}{c}\text { LVDP } \\
(\mathrm{mmHg})\end{array}$ & $\begin{array}{c}\mathrm{RPP} \\
\left(\mathrm{mmHg} / \mathrm{min} / 10^{3}\right)\end{array}$ & $\begin{array}{c}+\mathrm{dP} / \mathrm{dt}_{\max } \\
\left(\mathrm{mmHg} / \mathrm{s} / 10^{3}\right)\end{array}$ & $\begin{array}{c}-\mathrm{dP} / \mathrm{dt}_{\min } \\
\left(\mathrm{mmHg} / \mathrm{s} / 10^{3}\right)\end{array}$ \\
\hline EGCG-0 & $12.9 \pm 0.2$ & $281.0 \pm 8.8$ & $115.9 \pm 11.3$ & $34.0 \pm 2.9$ & $2.4 \pm 0.1$ & $-2.4 \pm 0.2$ \\
\hline EGCG-1 & $14.0 \pm 0.5$ & $285.4 \pm 8.4$ & $122.5 \pm 9.0$ & $34.8 \pm 2.6$ & $2.4 \pm 0.1$ & $-2.5 \pm 0.1$ \\
\hline EGCG-10 & $13.6 \pm 0.6$ & $299.4 \pm 7.2$ & $114.4 \pm 9.0$ & $34.4 \pm 3.1$ & $2.5 \pm 0.2$ & $-2.4 \pm 0.2$ \\
\hline
\end{tabular}

Values are mean \pm SEM. EGCG: polyphenol (-)-epigallocatechin gallate. EGCG-0, EGCG-1, and EGCG-10: 0, 1, and $10 \mu$ M of EGCG, respectively.

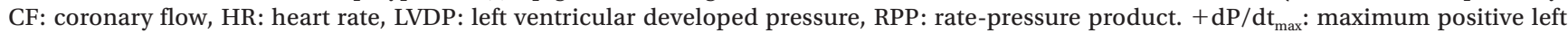
ventricular pressure derivative, $-\mathrm{dP} / \mathrm{dt}_{\min }$ : minimum negative left ventricular pressure derivative. There were no differences in baseline $\mathrm{CF}$ and cardiodynamics among groups.
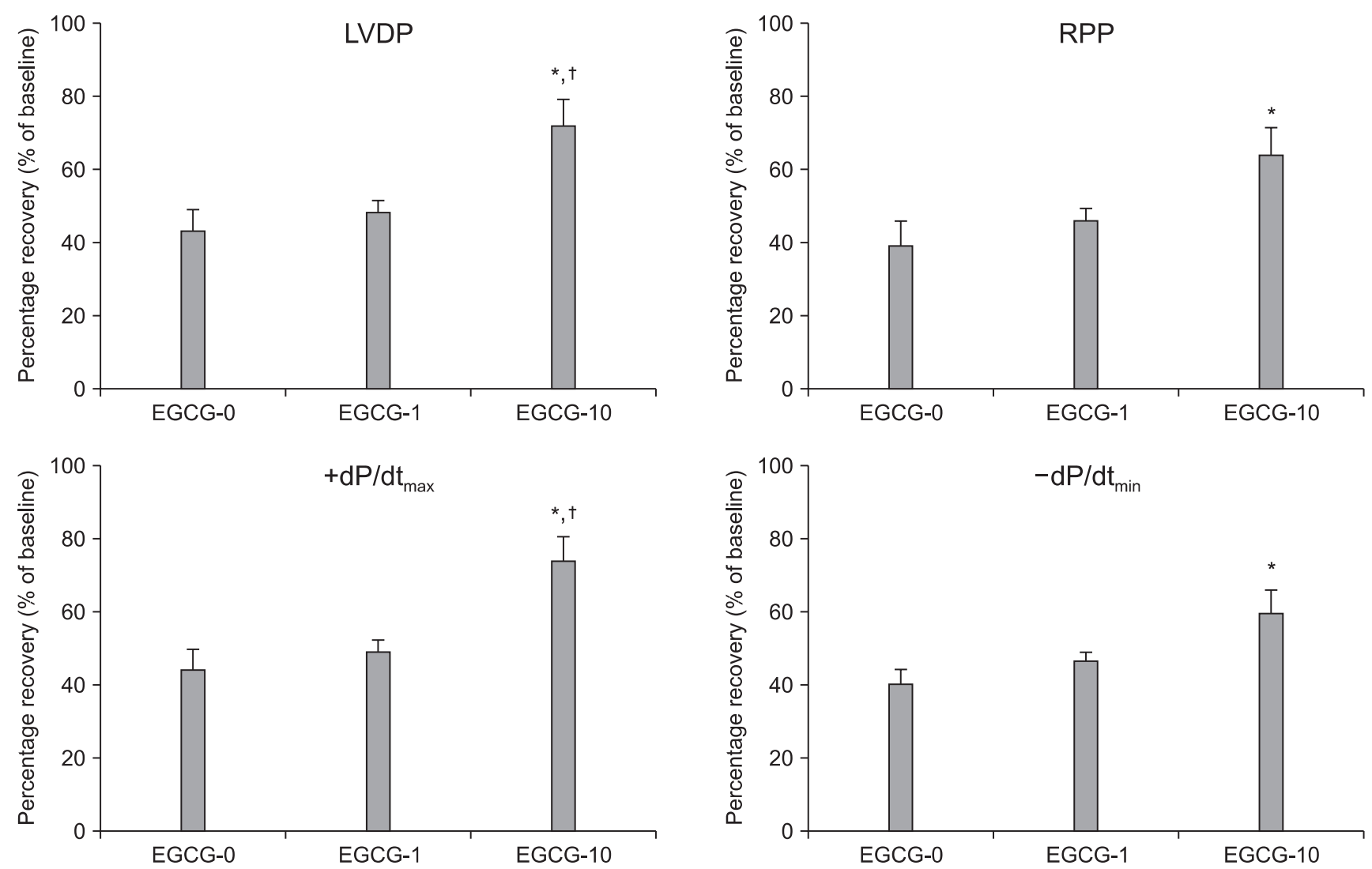

Fig. 2. Recovery of the left ventricular developed pressure (LVDP), rate-pressure product (RPP), and maximum $\left(+d P / d t_{\text {max }}\right)$ and minimum $\left(-\mathrm{dP} / \mathrm{dt}_{\min }\right)$ of first derivative of left ventricular pressure after $2 \mathrm{hrs}$ of reperfusion in isolated rat hearts. Rat hearts are treated 1 (EGCG-1) or $10 \mu \mathrm{M}$ (EGCG10 ) of polyphenol (-)-epigallocatechin gallate (EGCG). Values are expressed as mean \pm SEM. ${ }^{*} \mathrm{P}<0.05$ vs. EGCG-untreated hearts (EGCG-0), ${ }^{\dagger} \mathrm{P}$ $<0.05$ vs. EGCG-1. 


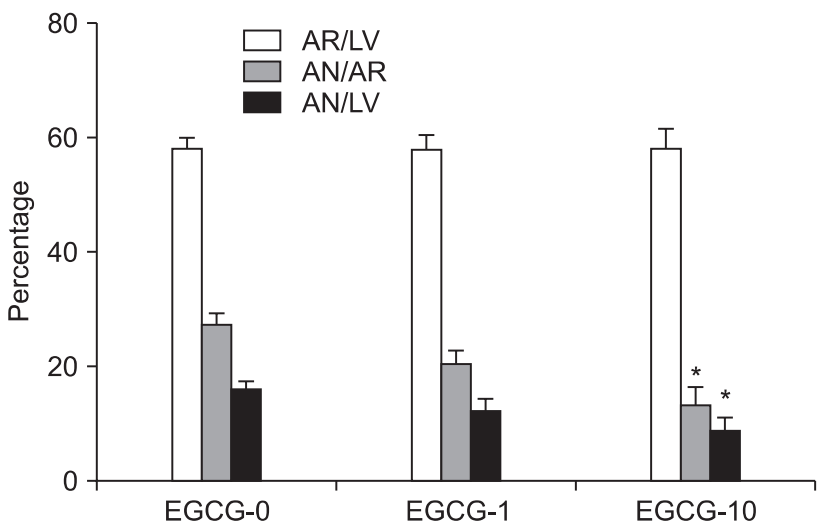

Fig. 3. AR/LV, AN/AR, and AN/LV as evaluated by triphenyltetrazolium chloride staining following $30 \mathrm{~min}$ regional ischemia and 2 hrs reperfusion in isolated rat heart model. Rat hearts are treated with 1 (EGCG-1) or $10 \mu \mathrm{M}$ (EGCG-10) of polyphenol (-)-epigallocatechin gallate (EGCG). EGCG-10 treated hearts significantly decrease AN/AR and AN/LV compared to EGCG-untreated hearts (EGCG$0)$. AR: area at risk, AN: area of necrosis, LV: volume of left ventricle. Values are expressed as mean \pm SEM. ${ }^{*} \mathrm{P}<0.05$ vs. EGCG- 0 .

either group EGCG-0 or group EGCG-1 ( $\mathrm{P}=0.01, \mathrm{P}=0.036$, respectively) (Fig. 2). The RPP for group EGCG-0 was $38.8 \pm 7.9 \%$; for group EGCG-1 was $46.1 \pm 3.6 \%$; and for group EGCG-10 was $63.9 \pm 9.9 \%$, which was significantly higher than the RPP in group EGCG-0 $(\mathrm{P}=0.016)$.

The $+\mathrm{dP} / \mathrm{dt}_{\max }$ for group EGCG-0 was $44.1 \pm 6.8 \%$; for group EGCG- 1 was $49.1 \pm 3.8 \%$; and for group EGCG-10 was $73.9 \pm$ $10.4 \%$, which was significantly higher than the $+\mathrm{dP} / \mathrm{dt}_{\max }$ in groups EGCG-0 and EGCG-1 ( $\mathrm{P}=0.009, \mathrm{P}=0.029$, respectively). The $-\mathrm{dP} / \mathrm{dt}_{\min }$ for group EGCG-0 was $40.2 \pm 4.6 \%$; for group EGCG-1 was $46.7 \pm 2.4 \%$; and for group EGCG-10 was $59.4 \pm$ $7.9 \%$, which was significantly higher than the $-\mathrm{dP} / \mathrm{dt}_{\min }$ for group EGCG-0 ( $\mathrm{P}=0.019)$.

For groups EGCG-0, EGCG-1, EGCG-10, the AR/LV values were $58.2 \pm 2.9 \%, 57.8 \pm 3.8 \%$, and $58.2 \pm 4.5 \%$, respectively. There were no significant differences among the groups in the development of regional ischemia in the LV (Fig. 3). The AN/ AR value for group EGCG-0 was $27.2 \pm 1.4 \%$; for group EGCG-1 was $20.3 \pm 2.9 \%$; and for group EGCG-10 was $13.2 \pm 4.0 \%$, which was significantly lower compared to group EGCG-0 $(\mathrm{P}=0.002)$. The AN/LV values for groups EGCG-0, EGCG-1, and EGCG10 were $15.9 \pm 1.2 \%, 12.0 \pm 2.3 \%$, and $8.7 \pm 3.1 \%$, respectively. Compared to group EGCG-0, the AN/LV in group EGCG-10 was significsantly lower $(\mathrm{P}=0.028)$.

\section{Discussion}

GT of $1 \mu \mathrm{M}$ administered during reperfusion in isolated rat hearts effectively reduced post-reperfusion myocardial necrosis. Ten $\mu \mathrm{M}$ of EGCG, the most abundant catechin in green tea, effectively reduced post-reperfusion myocardial necrosis, and improved cardiac hemodynamics, namely the recoveries of LVDP, RPP, $+\mathrm{dP} / \mathrm{dt}_{\max }$ and $-\mathrm{dP} / \mathrm{dt}_{\min }$.

Townsend et al. [12] first reported that $100 \mu \mathrm{M}$ of EGCG administered during ischemia successfully reduced myocardial necrosis and prevented ischemic injury in isolated rat hearts. The effects of EGCG administered during reperfusion were first reported by Aneja et al. [13]. In an in vivo experiment, EGCG administered during reperfusion caused a decrease in myeloperoxidase activity, which is a marker of neutrophil accumulation, an indicator of inflammatory response. They also reported that EGCG reduced plasma creatine phosphokinase activity. In cardiac tissue stained with hematoxylin and eosin, heart tissue trauma and necrosis were decreased in rats receiving EGCG. In the presented study, in which TTC stain was used to measure the degree of myocardial necrosis, $10 \mu \mathrm{M}$ EGCG administered during reperfusion caused significant decreases in AN/AR and AN/LV values compared to other groups. .

Although $1 \mu \mathrm{M}$ of green tea extract was shown to effectively decrease myocardial necrosis, $1 \mu \mathrm{M}$ EGCG had no effect in reducing myocardial necrosis in this study. However, $10 \mu \mathrm{M}$ EGCG was effective. Although the exact reason for this result is not known, there are other catechins besides EGCG in green tea, such as EGC, ECG, and EC, which may also have cardioprotective effects. The discovery that EGCG has inotropric effects on isolated rat hearts supports this possibility. It has been reported that when green tea leaves are heated, the epimerization of EGCG produces (-)-gallocathechin-3-gallate (GCG), which like EGCG, protects the heart after reperfusion [16]. This may be why $1 \mu \mathrm{M}$ green tea reduced myocardial necrosis, even though in the present study, $1 \mu \mathrm{M}$ EGCG had no effect. Further research is required to resolve this issue.

Aneja et al. [13] has reported that when they administered EGCG during reperfusion, the RPP measured after reperfusion was not different between the groups where EGCG had been administered and where it had not been. In the present study, however, the RPP in the group in which $10 \mu \mathrm{M}$ EGCG was administered, was significantly higher after $2 \mathrm{~h}$ of reperfusion compared to the group in which EGCG had not been administered. One reason for difference in results may be due to differences in methods of calculation. Aneja et al. [13] calculated the RPP using the product of the mean arterial pulse pressure and the heart rate; whereas the authors of this study used the product of LVDP and the heart rate. After reperfusion, compared to the other groups, in the group administered $10 \mu \mathrm{M}$ EGCG, the LVSP was restored, and LVEDP decreased. This increased LVDP recovery, which triggered RPP recovery. Other reasons why the RPP results of the present study may differ from the RPP results of Aneja et al. [13] may be the different testing methods, different amounts of administered EGCG, 
and different administration times. However, the LVDP and RPP enhancements in the present study are similar to the results of Townsend et al. [12], where, during ischemia, they administered EGCG and stimulated LVDP recovery after reperfusion. EGCG administration, whether during ischemia or reperfusion, consequently enhances cardiac hemodynamics. However, in assessing the damage caused by cardiac ischemia and reperfusion, the cardiac hemodynamic indicies that reflect mechanical function may not be the suitable [17]. In evaluating reperfusion injury, measuring the degree of cardiac necrosis may be a more reliable indicator.

Most biological studies assessing EGCG used concentrations ranging from $10 \mu \mathrm{M}$ to $100 \mu \mathrm{M}$. The present study observed the reduction of cardiac necrosis with administration of $10 \mu \mathrm{M}$. However, a human blood concentration of $10 \mu \mathrm{M}$ EGCG can only be achieved if the subjects under fasting were to ingest 50-60 cups of green tea. In addition, even by ingesting 800 mg capsules of pure EGCG, it would be difficult to achieve a concentration greater than $5 \mu \mathrm{M}$ [6]. Therefore, $10 \mu \mathrm{M}$ EGCG, which proved to be effective in reducing cardiac necrosis, is impossible to achieve for human beings by just drinking green tea. Although not yet clinically feasible, therapeutic levels may be possible by intravenous administration.

Recently, there have been studies reporting that green tea has reduced the incidence of coronary artery disease and related deaths in human beings. Nakachi et al. [18] reported that drinking more than 10 cups of green tea reduced the likelihood of cardiovascular disease-related death. Sano et al. [19] reported that when patients undergoing coronary angiography were separated into groups with and without coronary occlusion, the group without coronary occlusion drank significantly much more green tea, about 6 glasses a day. Kuriyama [20] also showed in an epidemiological survey that drinking green tea reduced the risk of cardiovascular diseases. A long-term cohort study [21] on 40,000 subjects reported that green tea reduced death rates, especially deaths due to cardiovascular diseases. However, there are still no objective data on the exact amount of green tea needed to reduce the risk of cardiovascular diseases. However, it is unclear whether the effects of green tea may differ in relation to other factors such as race, culture, region, diabetes, hypertension, and hyperlipidemia. More research is required.

The studies on whether EGCG reduces the rates of ischemiaand reperfusion-related damage in animals and human beings so far have not yet been able to explain the mechanisms behind reduction. Townsend et al. [12] suggested that the cardioprotective effect of EGCG is due to the reduction of phosphorylation and activation of pro-apoptotic factors, and the signal transduction and activator of transcription (STAT)1. Potenza et al. [22] stated that EGCG is cardioprotective, because it triggers the production of nitric oxide and activates phosphatidylinositol-3-OH kinase. Li et al. [15] believes that EGC, a green tea catechin, causes myocardial contraction due to protein kinase $\mathrm{C}$ epsilon. Although the activation of $\mathrm{G}$ proteincoupled receptors (GPCR) is involved in the mechanism of intracellular messaging in the prevention of reperfusion injury [23], the relationship between EGCG and GPCR activation has yet to be illuminated.

Recent discoveries have illuminated the main mechanisms involved in the cardioprotective effect after reperfusion injury, which include the ERK1/2 or PI3-kinase as the main intracellular control pathway $[24,25]$. However, Dreger et al. [26] reported in their study using cardiac muscle cells, that the activation of prosurvival signaling kinases and the upregulation of antioxidative enzymes had no effect on the cardioprotective activity of EGCG. Also, it has recently been discovered that during the first few minutes of reperfusion, the inhibition of the opening of the mitochondrial permeability transition pore (MPTP) is the final target of the cardioprotective mechanism of EGCG $[27,28]$. More detailed research on the intracellular control pathway of cardioprotection by EGCG, including the inhibition of the opening of MPTP is needed.

In conclusion, the results of this study show that EGCG, the primary bioactive substance of green tea, reduced reperfusioninduced cardiac necrosis rates in isolated mouse hearts. In addition, EGCG administered during reperfusion reduced stunning after reperfusion. However, detailed research on the intracellular pathways involved in the prevention of cardiac reperfusion damage by EGCG and on whether green tea is effective in reducing cardiac reperfusion damage in human beings, is needed.

\section{Acknowledgements}

The authors would like to acknowledge YN Kim in department of medical information for his instrumental assistance and SK Suh for his skilled assistance.

\section{References}

1. Zhang A, Zhu QY, Luk YS, Ho KY, Fung KP, Chen ZY. Inhibitory effects of jasmine green tea epicatechin isomers on free radicalinduced lysis of red blood cells. Life Sci 1997; 61: 383-94.

2. Mabe K, Yamada M, Oguni I, Takahashi T. In vitro and in vivo activities of tea catechins against Helicobacter pylori. Antimicrob Agents Chemother 1999; 43: 1788-91.

3. Han MK. Epigallocatechin gallate, a constituent of green tea, suppresses cytokine-induced pancreatic beta-cell damage. Exp Mol Med 2003; 35: 136-9.

4. Hara S, Endo T, Kuriiwa F, Kano S. NADPH-dependent reaction of paraquat in mouse brain microsomes. Toxicol Lett 1990; 54: 271-7. 
5. Yang CS, Maliakal P, Meng X. Inhibition of carcinogenesis by tea. Annu Rev Pharmacol Toxicol 2002; 42: 25-54.

6. Lim DY, Lee ES, Park HG, Kim BC, Hong SP, Lee EB. Comparison of green tea extract and epigallocatechin gallate on blood pressure and contractile responses of vascular smooth muscle of rats. Arch Pharm Res 2003; 26: 214-23.

7. Miura Y, Chiba T, Tomita H, Koizumi H, Miura S, Umegaki K. Tea catechins prevent the development of atherosclerosis in apoprotein E-deficient mice. J Nutr 2001; 131: 27-32.

8. Hertog MG, Feskens EJ, Hollman PC, Katan MB, Kromhout D. Dietary antioxidant flavonoids and risk of coronary heart disease: the Zutphen Elderly Study. Lancet 1993; 342: 1007-11.

9. Jin JY, Park SH, Bae JH, Cho HC, Lim JG, Park WS. Uncoupling by (-)-epigallocatechin-3-gallate of ATP-sensitive potassium channels from phosphatidylinositol polyphosphates and ATP. Pharmacol Res 2007; 56: 237-47.

10. Park JW, Jang YH, Kim JM, Lee H, Park WK, Lim MB. Green tea polyphenol (-)-epigallocatechin gallate reduces neuronal cell damage and up-regulation of MMP-9 activity in hippocampal CA1 and CA2 areas following transient global cerebral ischemia. J Neurosci Res 2009; 87: 567-75.

11. Jang YH, Lee YC, Park NH, Shin HY, Mun KC, Choi MS. Polyphenol (-)-epigallocatechin gallate protection from ischemia/reperfusioninduced renal injury in normotensive and hypertensive rats. Transplant Proc 2006; 38: 2190-4.

12. Townsend PA, Scarabelli TM, Pasini E, Gitti G, Menegazzi M, Suzuki H. Epigallocatechin-3-gallate inhibits STAT-1 activation and protects cardiac myocytes from ischemia/reperfusion-induced apoptosis. FASEB J 2004; 18: 1621-3.

13. Aneja R, Hake PW, Burroughs TJ, Denenberg AG, Wong HR, Zingarelli B. Epigallocatechin, a green tea polyphenol, attenuates myocardial ischemia reperfusion injury in rats. Mol Med 2004; 10: 55-62.

14. Lee YC, Jang YH, Kim JM, Kim AR, Kim CJ, Kim YN. Effect of a kappa-opioid receptor agonist U50488H given at early reperfusion phase in isolated rat hearts. Korean J Anesthesiol 2008; 54: S29-34.

15. Li D, Yang C, Chen Y, Tian J, Liu L, Dai Q. Identification of a PKCepsilon-dependent regulation of myocardial contraction by epicatechin-3-gallate. Am J Physiol Heart Circ Physiol 2008; 294: H345-53.

16. Hirai M, Hotta $Y$, Ishikawa N, Wakida $Y$, Fukuzawa $Y$, Isobe $F$. Protective effects of EGCg or GCg, a green tea catechin epimer, against postischemic myocardial dysfunction in guinea-pig hearts.
Life Sci 2007; 80: 1020-32.

17. Lochner A, Genade S, Moolman JA. Ischemic preconditioning: infarct size is a more reliable endpoint than functional recovery. Basic Res Cardiol 2003; 98: 337-46.

18. Nakachi K, Matsuyama S, Miyake S, Suganuma M, Imai K. Preventive effects of drinking green tea on cancer and cardiovascular disease: epidemiological evidence for multiple targeting prevention. Biofactors 2000; 13: 49-54.

19. Sano J, Inami S, Seimiya K, Ohba T, Sakai S, Takano T. Effects of green tea intake on the development of coronary artery disease. Circ J 2004; 68: 665-70.

20. Kuriyama S. The relation between green tea consumption and cardiovascular disease as evidenced by epidemiological studies. J Nutr 2008; 138: 1548S-1553S.

21. Kuriyama S, Shimazu T, Ohmori K, Kikuchi N, Nakaya N, Nishino Y. Green tea consumption and mortality due to cardiovascular disease, cancer, and all causes in Japan: the Ohsaki study. JAMA 2006; 296: 1255-65.

22. Potenza MA, Marasciulo FL, Targuinio M, Tiravanti E, Colantuono G, Federici A. EGCG, a green tea polyphenol, improves endothelial function and insulin sensitivity, reduces blood pressure, and protects against myocardial I/R injury in SHR. Am J Physiol Endocrinol Metab 2007; 292: E1378-87.

23. Xi JK, Jin YZ, Cui X, Xu Z. Cardioprotection against reperfusion injury: updated mechanisms and strategies. Sheng Li Xue Bao 2007; 59: 553-61.

24. Hausenloy DJ, Tsang A, Yellon DM. The reperfusion injury salvage kinase pathway: a common target for both ischemic preconditioning and postconditioning. Trends Cardiovasc Med 2005; 15: 69-75.

25. Hausenloy DJ, Yellon DM. Survival kinases in ischemic preconditioning and postconditioning. Cardiovasc Res 2006; 70: 24053.

26. Dreger H, Lorenz M, Kehrer A, Baumann G, Stangl K, Stangl V. Characteristics of catechin- and theaflavin-mediated cardioprotection. Exp Biol Med (Maywood) 2008; 233: 427-33.

27. Hausenloy DJ, Maddock HL, Baxter GF, Yellon DM. Inhibiting mitochondrial permeability transition pore opening: a new paradigm for myocardial preconditioning? Cardiovasc Res 2002; 55 : 534-43.

28. Hausenloy DJ, Yellon DM. The mitochondrial permeability transition pore: its fundamental role in mediating cell death during ischaemia and reperfusion. J Mol Cell Cardiol 2003; 35: 339-41. 